\title{
Auge y decadencia del anarcosindicalismo en España
}

\author{
JULIAN CASAnova
}

Ochenta años. Eso es lo que duró la semilla, la siembra y la cosecha anarquista, desde que Fanelli llegó a España en noviembre de 1868 hasta el exilio de miles de militantes en los primeros meses de 1939. Ochenta años acompañados de una frenética actividad propagandística, cultural y educativa; de terrorismo y de violencia; de huelgas e insurrecciones; de revoluciones abortadas y sueños igualitarios.

No ha pasado inadvertida esa presencia anarquista. Su leyenda de honradez, sacrificio y combate fue cultivada durante décadas por sus seguidores. Sus enemigos, a derecha e izquierda, siempre resaltaron la afición de los anarquistas a arrojar la bomba y empuñar el revólver. Son, sin duda, imágenes exageradas a las que tampoco hemos escapado los historiadores que tan a menudo nos alimentamos de esas fuentes, apologéticas o injuriosas, sin medias tintas. Imágenes que anticiparon Díaz del Moral, Brenan o el mismo Anselmo Lorenzo, y que se han hecho también con un importante hueco en la literatura, con La bodega de Blasco Ibáñez, Aurora Roja de Pio Boraja, La verdad sobre el caso Savolta de Eduardo Mendoza, o más recientemente, La hija del canibal de Rosa Montero. Una veta, en fin, explotada por el cine, por Ken Loach y su Tierra y Libertad o Vicente Aranda en Libertarias.

Desde Fanelli al exilio republicano, el anarquismo arrastró tras su bandera roja y negra a sectores populares diversos y muy amplios. Había algo de anormal, de excepcional, de atípico, en todo ello, porque lo normal hubiera sido el socialismo, la "doctrina científica" que necesitaba el proletariado, por utilizar la frase con la que Julián Besteiro, con la Segunda República en el horizonte, trataba de convencer a los obreros zaragozanos 
para que abandonasen el anarquismo, «la última consecuencia lógica de la libertad burguesa».

Anormal, sobre todo, porque ese anarquismo había arraigado en Barcelona, en la ciudad más industrial y moderna de España, en donde además nunca había podido abrirse paso el socialismo organizado. Ahí residía también la excepcionalidad: no se podía explicar sólo como un fenómeno de rebeldía primitiva, de campesinos desesperados, de países agrícolas, de "regiones de sol", como decía Díaz del Moral. Y como anormal fue tratado por socialistas como Besteiro, por marxistas y comunistas como Maurín, por perspicaces estudiosos como Diaz del Moral, Brenan o Hobsbawm. Tan peculiar era el asunto que obligó a los primeros historiadores que se acercaron con rigor a su historia a dar explicaciones sobre su arraigo, una tarea en la que destacaron el desaparecido Antonio María Calero y José Álvarez Junco. En realidad, había otras muchas cosas peculiares en la historia contemporánea de España, como el republicanismo, el anticlericalismo, los nacionalismos, las guerras civiles o los golpes de Estado. Y tampoco parece que en lo demás países el socialismo cosechase éxitos sonados: Werner Sombart intentaba responder en 1906 al enigma de "¿Por qué no hay socialismo en Estados Unidos?»; y en Europa occidental, un marco comparativo más adecuado para España, hasta la Primera Guerra Mundial sólo una pequeña proporción de los obreros pertenecían a organizaciones políticas o sindicales socialistas $y$, en términos electorales, únicamente en Alemania se había consolidado un influyente partido socialista de masas. Durante mucho tiempo poco importó, sin embargo, todo eso: en unos sitios porque había anarquismo y en otros porque no había socialismo, las diversas historias nacionales buscaban, y encontraban sus pecualiaridades.

Convendría, por ello, recordar de nuevo algo que las investigaciones más recientes parecen probar: el anarquismo no fue un fenómeno «excepcional» y "extraordinario" de la historia de España, si se entiende por "normal» y "ordinario» lo que sucedía en los restantes países de Europa occidental, hasta bien entrado el siglo $x x$, hasta que se produjo el tránsito del anarquismo al anarcosindicalismo, desde formas de organización basadas en grupos de afinidad ideológica hasta un encuadramiento sindical más formal y disciplinado asentado en el oficio o ramo de la producción en que trabajasen los afiliados. Sólo con la constitución y consolidación de la CNT como un movimiento de masas en los años 1917-1921 y 1931-1937 comenzó la "atipicidad» española, porque por esas fechas -y salvo en Argentina y Suecia- el sindicalismo revolucionario, antipolítico y de acción directa, había desaparecido del resto del mundo. 
Hasta esa conservación en anarcosindicalismo, España presenció tendencias en el asociacionismo obrero muy similares a Francia o Italia: adscripción a las posiciones bakuninistas, declive de la Primera Internacional, aparición del terrorismo en los años noventa y expansión de la doctrina del sindicalismo revolucionario durante los primeros años del siglo xx. Ni siquiera la Confederación Nacional del Trabajo (CNT), fundada en 1910, fue un fenómeno persistente y estable: mantuvo sólo una importante implantación en periodos muy concretos y, salvo en Cataluña y en algunas ciudades como Sevilla o Zaragoza, compartió esa presencia con la UGT, un sindicalismo que cultivó también, hasta la Segunda República, la tradición antipolítica y antiestatal heredada de la Primera Internacional.

Pero, aunque inestable y menos persistente de lo que se ha supuesto, dominado por la discontinuidad geográfica y cronológica, el anarquismo estaba ahi, desapareciendo y volviendo a la luz, con sus explosiones de protesta, con su proyecto social de libertad, de colectivización de los medios de producción, de abolición del Estado, de organización de la sociedad futura sin coerción, objetivos a los que se llegaria a través del antipoliticismo, de la negación de las luchas electorales y parlamentarias, auténticas señas de identidad del movimiento.

No fue sólo un fenómeno español, pero acabó identificado con España, "país de excepción», sentenciaba Besteiro, después de que los bolcheviques hubieran eliminado en Rusia «los restos de anarquismo». Eso lo decia el líder socialista en 1930. Y faltaba todavía la República, y la guerra civil, la edad de oro del anarquismo español, antes de ser aniquilado por la represión franquista y engullido por la modernidad. Historia solemne, heroica, amenazadora. Detengámonos en ella.

\section{LA SEMILLA}

El paso de Fanelli por España levantó entusiasmos, si creemos el famoso relato que del hecho dejo para la posteridad Anselmo Lorenzo en El proletariado militante. Fanelli, delegado de la bakuninista Alianza de la Democracia Socialista, apenas encontró dificultades para convencer al grupo de obreros que se reunió en Madrid en casa de Rubau Donadeu de la necesidad de constituir un núcleo organizador de la sección española de la Asociación Internacional de Trabajadores. No hablaba español y los españoles allí presentes entendían poco el francés o el italiano. No importaba. Su «mímica expresiva» los poseyó. Según Díaz del Moral, 
que exageró todavia más esa conservación, "sus grandes ojos negros brillaban con ráfagas de cólera cuando lanzaba anatemas contra los tiranos; su voz, de timbre metálico, tronaba como el huracán, maldiciendo a los explotadores y a los déspotas, y adquiría inflexiones de caricia y de compasión infinita describiendo los terribles sufrimientos de los humildes y las horrendas torturas del trabajador. Cosa horribile!, spaventosa! A los pocos minutos, el auditorio en pleno era presa de un entusiasmo delirante".

Tras adoctrinar al grupo de Madrid, en el que además de Lorenzo y Rubau Donadeu estaban Francisco Mora y González Morago, hizo lo propio en Barcelona, «en donde halló acogida en un grupo de intelectuales», entre quienes se encontraban Rafael Farga Pellicer, el médico Gaspar Sentiñón y el estudiante García Viñas. El resto resultó sencillo para esos apóstoles de la revolución: «en posesión ya de las verdades absolutas, reducido todo otro conocimiento a una deducción, se consagraron a combatir los sofismas que la falsa ciencia burguesa venía difundiendo por el mundo durante la serie de los siglos".

Pese a lo atractivo que resulta ese relato, no fueron, sin embargo, la "mímica expresiva" de Fanelli o las "lenguas de fuego" que descendieron sobre las cabezas de los iniciados en aquella reunión, los causantes de la expansión del internacionalismo y del bakuninismo por España. Fanelli se paseó por Madrid y Barcelona bajo una atmósfera de libertades, sin Monarquía, con los obreros luchando de nuevo por el reconocimiento del derecho de asociación, un asunto que había acompañado todas las etapas de la revolución liberal española, en 1840-1843, 18541856. La crítica moral y política del poder, el antipoliticismo bakuninista, el lenguaje político de la revolución, con sus acentos progresista, democrático-radical, socialista utópico, republicano, pudieron asentarse sobre una base ideológica, solidaria y proudhoniana, democrática en política, que estaban fermentando desde finales de los años cuarenta. Casi todos esos internacionalistas, bakuninistas, anarquistas de la primera generación, habian militado en el partido republicano, en el federalismo pimargalliano.

El llamado sexenio revolucionario cambió algo ese panorama porque las huelgas, los alzamientos de septiembre-octubre de 1869 y la República de 1873 contribuyerori a configurar y fortalecer una mejor definida conciencia obrera, antipolítica, alejada y momentáneamente desencantada del republicanismo político. No fue, por lo tanto, sólo el bakuninismo el que inspiró la Federación Regional Española (FRE), la organización formal de la Internacional en España, constituida en Barcelona en el Congreso de 
junio de 1870. La FRE se apoyó en una tradición política democrático-radical, cooperativista y asociacionista, a la que añadió el colectivismo y el antiestatismo, todo ello filtrado con las experiencias de los trabajadores, artesanos, campesinos, "proletarios" fabriles en Barcelona, durante esos conflictivos años. Duró poco, echada abajo la República a golpe de sable, pero creó una red de sociedades obreras, especialmente en Cataluña y Levante, de panfletos y periódicos, y adquirió una presencia notable en el discurso público, suscitando temores entre la gente de orden y esperanzas entre las capas populares.

Esa fusión entre el asociacionismo obrero, formas presindicales de resistencia, y el lenguaje político anarquista pudo volver pronto al escenario tras la creación en septiembre de 1881 de la Federación de Trabajadores de la Región Española (FTRE), que se expandió notablemente en Andalucía. Aunque tampoco duró, disuelta tras los crimenes de La Mano Negra, cuando el Gobierno emprendió una enérgica represión contra las organizaciones obreras, tomando como pretexto hechos ajenos a las actividades de la Internacional, como había sucedido en 1873 tras la Cantonal.

Y llegó la desorganización, la clandestinidad, el terrorismo de los años noventa, que florece en años de decadencia de la organización obrera, de marginalidad, provocado, si aceptamos la tesis de Núñez Florencio, por la brutalidad e intransigencia del poder, que alimenta los argumentos de los partidarios de la acción violenta, de la "propaganda por el hecho", de poner la química al servicio de la revolución. Eso del terrorismo es un fenómeno internacional, que produce fuera de España muchas más víctimas y de más importancia, incluyendo un Zar de Rusia, un Rey de Italia, una Emperatriz de Austria, un Presidente de Estados Unidos y otro en Francia. $Y$ extranjeros eran algunos de los terroristas que actuaron en España, como Angiolillo, Thioulouze, Ascheri, Girault... Pero también aquí dejó su huella, con actos sonados como el atentado contra Martínez Campos, la bomba del Liceo, ambos en 1893, la bomba contra la cola de la procesión del Corpus en Barcelona en junio de 1896 y el asesinato de Cánovas del Castillo en el balneario de Santa Águeda en agosto del año siguiente.

Muchos de esos atentados ocurrieron por venganza, represalias contra un poder que torturaba y condenaba a muerte a personas que nada tenían que ver con los atentados, que detenía indiscriminadamente a anarquistas, republicanos, librepensadores, sin garantías, reverdeciendo la leyenda de la "Inquisición española», haciendo pasar a la historia la fortaleza de Montjuich como el "castillo maldito", lugar de tortura y muerte, donde 
sería fusilado Ferrer i Guardia después de la Semana Trágica y Companys tras la guerra civil.

Barcelona concentró la mayoría de los atentados y las torturas, convirtiéndose en un centro anarquista internacional, aunque el terrorismo de la acción individual ligado al anarquismo desapareció con Cánovas, iniciándose con el siglo xx una nueva fase terrorista, que los anarquistas nunca reivindicaron, de explosiones indiscriminadas, que le colgaron a la capital catalana el nombre de "ciudad de las bombas". Pero para entonces, 1904-1909, otros fenómenos ocupaban mayor espacio y preocupaban más que el terrorismo: el republicanismo lerrouxista derrotaba a las candidaturas dinásticas con sonados éxitos electorales y las sociedades obreras catalanas encontraban en Solidaridad Obrera nuevas armas de lucha ya ensayadas por el sindicalismo revolucionario francés y que cristalizaban en 1910 en la CNT. Habían pasado cuarenta años desde la llegada de Fanelli, tiempo suficiente para que eso que se conoce como el anarquismo tomara forma. ¿Qué era el anarquismo? ¿Cómo se manifestaba?

Hace ya tıempo que José Álvarez Junco, en La ideología política del anarquismo español, identificó las dos corrientes doctrinales de las que bebía ese movimiento: el individualismo liberal y el comunitarismo socialista, una dualidad muy difícil de equilibrar en la práctica pese a todas sus llamadas a la armonía natural. El anarquismo parecía de entrada una utopía derivada de la filosofía optimista y armónica de la llustración, que mantuvo, como hijo del mismo tiempo que era, estrechas conexiones con las conspiraciones y sociedades secretas de tipo democrático radical, con el federalismo, con la fraseología romántico-populista. Pero al mismo tiempo iba mucho más lejos de lo proyectado por el racionalismo liberal y el populismo republicano, con su pretensión de abolir el Estado, colectivizar los medios de producción y sobre todo con su antipoliticismo, la verdadera seña de identidad del movimiento, el rasgo que marcó la ruptura con sus sucesivos compañeros de viaje, desde los federales a los socialistas, pasando por los republicanos.

El anarquismo que triunfó en España en el siglo xx, estrechamente unido ya al sindicalismo revolucionario, fue el "comunitario", el "solidario", el que confiaba en las masas populares para llevar a buen puerto la revolución. Durante las primeras décadas de gestación, sin embargo, coexistió con otro "individualista», más eurcpeo y elitista, que despreciaba a las masas y ensalzaba a las individualidades rebeldes, siguiendo a Stirner y Nielzsche. $Y$ así en esas tres últimas décadas de finales del siglo XIX convivieron las reivindicaciones legales en favor de la jornada 
de ocho horas con el terrorismo; las sociedades obreras, con los "grupos de afinidad" o de "acción". Emergieron numerosas publicaciones que, en su "labor ideológico-cultural», cumplieron tres funciones muy bien identificadas por Litvak: la creación de canales de comunicación e información, que incitaban a la lucha social; la crítica y oposición a «los lenguajes y canales institucionalizados por la clase detentadora del poder"; y la puesta en práctica de toda una red cultural alternativa, proletaria, "de base colectiva".

Al servicio de la causa se fundaron círculos y tertulias, ateneos obreros, escuelas laicas y racionalistas, coincidiendo con los republicanos y socialistas en muchas más cosas de lo que sus diferentes definiciones doctrinales daban a entender. Racionalismo, culto al pueblo y anticlericalismo aparecían como ingredientes básicos de esa cultura política común. Como común era el insurreccionalismo y el recurso a la conspiración, la mezcla de elementos de modernidad, de una visión del mundo, y de planteamientos "reaccionarios", inevitables en una sociedad como la española tan impregnada de tradición católica.

Esa mezcla de tradición y modernidad contagió al modelo político y organizativo de los anarquistas en España durante sus primeras décadas de expansión. "Creo que nos hacen falta dos organizaciones, una abierta, amplia, funcionando a la luz del día; la otra secreta, de acción», escribía Kropotkin en 1881. La propuesta, que reflejaba el acoso al que la policia y las fuerzas del orden sometían a los anarquistas en los diferentes países, resultó profética porque por esos dos caminos tácticos transitó el movimiento durante toda su historia, envuelto siempre en una doble organización: una de tipo asociativo, sindical, que federaría a las sociedades obreras alrededor de objetivos reivindicativos: y otra de tipo ideológico, que agruparían a los más "conscientes», centrada en la propaganda doctrinal y cuidando siempre de las desviaciones reformistas en el movimiento societario o sindical. La primera se impuso en momentos de libertades; la segunda, cuando la represión y la persecución apretaban. Pero no hay que olvidar que durante las primeras décadas hubo muchos más periodos de clandestinidad que de legalidad y que, salvo en España, sobre todo a partir de la fundación de la CNT en 1910, la segunda táctica identificó mucho más la forma de organización y de vida de los anarquistas. Pero también en España, el relegamiento de la pureza revolucionaria ante el reformismo que simbolizaban las reivindicaciones sindicales puso en alerta a los guardianes de esa pureza. La Federación Anarquista lbérica $(F A l)$ y su relación con el sindicalismo en los años de la Segunda República constituye el mejor ejemplo de esa dualidad. 
El recurso a la clandestinidad, a los sociedades secretas, al discurso ritual que caracterizaba a los grupos cerrados, contagió, según ha demostrado Clara E. Lida, a un "moderno movimiento revolucionario", haciéndole más indescifrable para historiadores y observadores, y a la vez menos vulnerable para el poder que se topó con toda una red de lazos de protección y solidaridad que se fortalecía en los momentos en que la expansión obrera y sindical flaqueaba. Según Lida, esa "sorprendente capacidad para integrar la moral colectiva de una cultura local a la ideología internacional de la clase", la capacidad de incorporar esos valores comunitarios al sistema de ideas y prácticas de clase, "les permitió de modo único en la historia del siglo XIX, integrar lenguajes antiguos a un moderno discurso político". Y ahí, posiblemente, residió otra de las posibles causas de la fascinación, atractivo y fortaleza que el movimiento tuvo en capas obreras, artesanas, periodistas bohemios y estudiantes, en medios tan diferentes como una sociedad obrera del campo andaluz, trabajadores manufactureros de pequeñas ciudades o proletarios industriales catalanes herederos de la tradición societaria decimonónica.

Todas esas tradiciones, formas organizativas y modos de vida del anarquismo bullían cuando se creó la CNT. Junto a la continuidad con esas experiencias, aparecieron en las tres primeras décadas del siglo xx nuevos ingredientes que tuvieron importantes consecuencias para la formación de las clases trabajadoras y la transformación del movimiento anarquista. El capitalismo industrial y la "explosión urbana" de algunas ciudades contribuyeron a consolidar en esos años la forma clásica de organización obrera, el sindicato. El discurso ritual de la clandestinidad y de la "subcultura" anarquista, de los "grupos de afinidad" y de "acción", de los ateneos obreros y de las escuelas laicas, se hizo público, se topó con un desarrollo paralelo de los lenguajes de clase, en la prensa, en los talleres y fábricas, en el campo y en la calle. Siguieron coexistiendo ambos discursos, el de la clandestinidad, de la acción, y el del sindicalismo; el de la visión corporativa del trabajo con el de la conciencia de clase. Pero el segundo se abrió camino sobre el primero, y de una vinculación laxa de las ideas libertarias se pasó a un encuadramiento más discipinado y de masas. El anarquismo transitó al anarcosindicalismo. $Y$ ahí comenzó, como ya se ha dicho, la «atipicidad» española.

\section{UN SINDICALISMO SIN ALIADOS POLITICOS}

Ese cambio de discurso, de ritos, y el paso de la clandestinidad a la actividad sindical coincidió también con un relevo generacional. Farga 
Pellicer, Francesc Tomás, Fermín Salvochea murieron antes de que apareciera la CNT. Anselmo Lorenzo, el "abuelo", murió en 1914. Y salieron al escenario público militantes que ya habian bebido de las visiones libertarias del mundo tan en boga en los años 90, como Joan Montseny, Teresa Mañé (Federico Urales y Soledad Gustavo, como se les conoció después) o Ricardo Mella, y sindicalistas de nuevo cuño, menos preocupados por el adoctrinamiento y más centrados en las reivindicaciones obreras. Si se exceptúa a los anarquistas de acción tan identificados con Durruti, Ascaso y García Oliver, que vivieron sus momentos dorados en la República y en los primeros meses de la guerra civil, casi todos los que se tomaron en serio al sindicalismo revolucionario, sus luchas diarias y sus sueños utópicos, forjaron sus rebeldías en los años de la Primera Guerra Mundial, participaron en la definición ideológica de ese sindicalismo en sus principales Congresos $(1918,1919,1931$ y 1936) y dirigieron u orientaron los grandes órganos periodísticos que, encabezados por Solidaridad Obrera, tanto identificaron al movimiento. Ahí sobresalieron Salvador Seguí, pronto asesinado, Ángel Pestaña y Joan Peiró, pero también Eleuterio Quintanilla, Eusebio Carbó, Valeriano Orobón Fernández o José Villaverde.

La historia abierta de la CNT, de movilización y expansión obrera, desde su fundación hasta la guerra civil, apenas sumó una docena de años. Durante ese tiempo, nunca tuvo aliados políticos, un partido que canalizara, representara y defendiera sus intereses a través de los mecanismos políticos parlamentarios. La ausencia de partidos políticos obreros fuertes y consolidados fue un fenómeno común a muchas sociedades europeas hasta la Primera Guerra Mundial y caracterizó a la española durante toda la Restauración. La persistencia de un sistema político pseudoparlamentario y corrupto, presidido por un Estado oligárquico e ineficaz, dejó en el sindicalismo español, tanto en el ugetista como en el cenetista, una impronta antipolítica y antiestatal, puesta una y otra vez de manifiesto en sus prácticas revolucionarias, que se constituyó, efectivamente, en la diferencia esencial entre el movimiento obrero español y los de los países europeos más avanzados.

La llegada de los representantes socialistas y de la UGT al gobierno del Estado modificó sustancialmente ese panorama en los primeros años de la República. Autoexcluidos de la representación política, los dirigentes de la CNT, especialmente los que comenzaron a dominar la organización desde comienzos de 1932, pudieron mantener la llama de la pureza, la fuerza de un mensaje anarquista enfrentado a esa realidad social y política tan perversa. $Y$ ahí se manifestaba de nuevo la atipicidad española: en la existencia de un sindicalismo antipolítico de masas que podía defender su 
proyecto al margen de las instituciones políticas y parlamentarias. En el resto de Europa, un sindicalismo de ese tipo era ya en los años treinta un objeto de historia.

La CNT era un movimiento dominado en términos generales por preocupaciones sindicales, independiente de los partidos políticos, pero para acceder al control de la organización se requería un mínimo conocimiento de las ideas libertarias. Se establecía así una diferencia entre los dirigentes, la militancia de base y los afiliados. Los primeros constituían el sector más consciente y experimentado en los principios básicos de la organizacićn, en la comprensión de los planteamientos doctrinales, conseguida a través de la lectura de libros, panfletos y prensa. Por debajo y al lado de esos dirigentes habia siempre un grupo considerable de militantes, informados de los acontecimientos políticos y sociales, de las posiciones de la organización, que solían leer la prensa, participar en las reuniones de los sindicatos y acudian en ocasiones a los ateneos y bibliotecas en busca de esa necesaria formación que les mantenía en la práctica militante. Quedaban, por último, los afiliados, que, con altibajos, siempre son durante ese período varios cientos de miles. Su vinculación con la organización era normalmente muy laxa: cotizaban, y muchas veces los tenían que perseguir para que lo hicieran, no acudian por lo general a los locales del sindicato o sección y participaban, dependiendo del grado de satisfacción o éxito que obtenían, en los conflictos laborales y en las movilizaciones de protesta. Para la mayoría de ellos, la CNT defendía las condiciones de vida de los trabajadores y luchaba por mejorarlas; para los dirigentes y el sector más militante, el anarcosindicalismo estaba llamado a transformar revolucionariamente la sociedad.

Las vías de formación ideológica que servían para dar el salto a la dirección se situaban en ámbitos "extrasindicales": ateneos libertarios, escuelas racionalistas, grupos de afinidad y una variada oferta de manifestaciones culturales que se convirtieron, sobre todo en los centros urbanos, en las auténticas señas de identidad de los militantes "con ideas". Dado que los sindicatos no eran los que proporcionaban esos canales de formación, el debate ideológico aparecía dominado por los dirigentes y el sector más activo y no se extendía a toda la organización. Se erigía de esa forma una frontera entre esa minoría adiestrada y la mayoría de los afiliados, alejados de cualquier discusión interna. Como consecuencia, casi inevitable, de esa importancia concedida a la formación y al conocimiento de las ideas, la militancia y el nivel cultural se daban la mano. En una sociedad con altas tasas de analfabetismo, especialmente entre los obreros, jornaleros del campo y mujeres, tales requisitos culturales condicionaban -e impedian - la participación activa de la mayoría de los afi- 
liados en los debates internos. Quienes impartían doctrina, recorrian pueblos y ciudades en "excursiones de propaganda", actuaban como oradores en los mítines y podían llegar a formar parte de los consejos de redacción de la prensa anarquista, eran una minoría de hombres, y rara vez mujeres, inquebrantables creyentes en la fuerza redentora de la cultura y las ideas.

Sería engañoso, por consiguiente, considerar que la CNT era diferente en ese asunto a las demás organizaciones de masas. El mito forjado en torno a la activa participación de todos sus miembros en las decisiones adoptadas se derrumba cuando se ponen en contraste los principios rectores de la Confederación y la forma habitual de funcionamiento. Algo que obliga a romper también la identificación entre trabajadores afiliados y dirigentes, entre la clase obrera y el movimiento anarcosindicalista.

Y lanzados ya a romper tópicos, habrá que reconocer que muchas cosas unieron a las culturas y prácticas de los dos sindicalismos, el de la CNT y el de la UGT, durante las tres primeras décadas del siglo $x x$, pese a las siempre señaladas diferencias en torno a la estructura orgánica, la ideología y los métodos de movilización. En realidad, como ha señalado Santos Juliá, los dos sindicalismos compartían elementos de una misma tradición, "como su desconfianza ante los partidos políticos y, en general, el parlamentarismo, su antiestatismo y la absoluta certeza en la necesidad de la revolución como acontecimiento natural, que ha de venir algún día, determinado por una especie de ley biológica y protagonizado por la clase obrera organizada en sindicatos y en el que los partidos políticos no tendrian realmente ningún papel que jugar».

Los posibles acercamientos se convirtieron, sin embargo, en odios desde el primer soplo republicano en la primavera de 1931. Desde el momento en que las nuevas atribuciones otorgadas a la UGT, con su integración en el aparato del Estado y la consolidación del corporativismo obrero inaugurado por la Dictadura de Primo de Rivera, superaban la «tradicional acción sindical» y concedían un trato de favor descarado a esa organización obrera, fundamentalmente en el control del trabajo, un bien escaso en aquellos tiempos. Algo que exigía, en palabras de Largo Caballero, ministro de Trabajo, "reducir al mínimo la llamada acción directa".

La CNT percibió ese favoritismo que le alejaba de su aspiración de conseguir el mismo monopolio de la negociación laboral que la UGT pretendía por otros medios, y se lanzó a una disputa abierta que al principio sólo contemplaba advertencias y amenazas, para manifestarse más tarde en coacciones y violencia. El comportamiento, muchas veces autónomo, de las fuerzas del orden, la persecución de formas pacíficas de manifes- 
tar la protesta y la detención de cientos de militantes cenetistas, bloqueó la estrategia de los dirigentes más moderados y nutrió la de los más intransigentes. Los comités pro-presos, la auténtica forma de "trabazón" entre ese radicalismo y la CNT, florecieron por todas partes y dominaron el orden del día de muchas reuniones sindicales. En los meses posteriores al Congreso, las protestas radicales derivaron en una lucha abierta contra el régimen republicano y sus mecanismos de defensa. Tras el primer intento insurreccional de enero de 1932, la ruptura con ese régimen era ya definitiva y la escisión en la organización anarcosindicalista estaba servida.

\section{LA CALLE FRENTE AL PARLAMENTO}

$Y$ es que sin aliados politicos y alejados de un gobierno que emprendió reformas que les afectaban, los sindicatos cenetistas comenzaron a movilizar a sus afiliados en la calle, a ocupar un espacio en el que se increpaba y combatía al Estado. Salir a la calle, más acción y menos palabras, se instituyć como «el acto revolucionario por excelencia». Y la calle era también el lugar donde se debian dirimir las diferencias existentes en una organización revolucionaria. Así se lo recordaba Durruti a Ricardo Fornells, uno de los firmantes del "manifiesto de los Treinta", expulsado del Sindicato de Alimentación de Barcelona: a los "treintistas" sólo les tendería la mano "en la calle, cuando le demuestren que son revolucionarios".

Entre mayo y julio de 19.31 la CNT declaró huelgas, a las que se sumaron en algunos casos los comunistas, que dejaron bastantes muertos en la calle, como en Pasajes y Sevilla, y que malograron no pocas ilusiones de los sindicalistas más moderados, de esos que esperaban que las libertades y esperanzas inauguradas con la República sirvieran para fortalecer la organización.

La «guerra civil» entre las dos prácticas sindicales se intensificó en la huelga general convocada por el Sindicato Único de Mineros de Asturias en junio y escaló un peldaño más hacia el abismo en la huelga nacional de teléfonos decretada por los sindicatos anarcosindicalistas para toda Esparia a comienzos de julio. La huelga contó con la resistencia de los otros tres sindicatos con implantación en la compañía y con la oposición de Maura a que los huelguistas negociaran directamente con ésa. Los enfrentamientos con las fuerzas de orden produjeron varios muertos, hubo numerosos detenidos y cientos de despedidos que, lejos de llevar a la reflexión sobre el fracaso de un corflicto planteado de forma precipitada, 
disparó la desconfianza ante un régimen que, al no «hacerse respetar por las vias y procedimientos de la equidad y del derecho (...) está condenado a morir prematuramente?.

El sector más puro del anarquismo encontró en los muertos y la represión un resorte para la movilización contra la República y contra quienes dirigian la CNT en ese momento. "El crimen, método de gobierno", comenzó a difundirse en los medios libertarios tras los sucesos de Pasajes y Sevilla. A medida que los conflictos se endurecían, arreciaban las jornadas de protesta contra la represión, contra la Ley de Defensa de la República, contra las deportaciones tras el primer intento insurreccional de enero de 1932. Eran muchos los conflictos planteados por objetivos meramente reivindicativos, para conseguir seguros de accidente y subsidios de enfermedad, para presionar en favor de mejoras salariales o hacer cumplir las bases presentadas a los patronos, protestas contra el seguro obligatorio de maternidad, pero la retórica, y las acciones que la fomentaban, iban por otro camino, por el de las visiones apocalípticas que anunciaban «el derrumbe total del mundo capitalista y autoritario". $Y$ aunque tampoco faltaron voces, como las que solían venir por aquel entonces desde Asturias que pedian "un periodo de calma, sin tantas huelgas y conflictos (...) para poder presentar un organismo confederal bien constituido", las que iban imponiéndose poco a poco eran otras, aquellas que insistían en que España estaba "secuestrada por la Guardia Civil», toda ella era una "cárcel de trabajadores", que confirmaba lo que ellos ya sabían: "que donde gobierna la socialdemocracia, es mucho más autoritaria y feroz que cualquier monarquía autoritaria y feudalista».

Fue a partir de enero de 1932 cuando esa retórica sobre el derramamiento de "sangre proletaria" se incorporó a los medios de difusión anarquistas de una forma definitiva. Tras la masacre de Arnedo, la insurrección de Figols y las subsiguientes deportaciones de cenetistas parecía muy difícil salvar las distancias entre una República «represiva" y "un proletariado de una manera creciente desligado ya de toda ilusión democrática".

Poco habian durado las ilusiones, el margen de confianza que algunos dirigentes como Galo Díez habían demandado en el Congreso Extraordinario de la CNT celebrado en Madrid en junio de 1931. Y quedaban todavía las insurrecciones de enero y diciembre de 1933, obra de grupos anarquistas iluminados por visiones catastrofistas, aunque no es en la escasa preparación, en la "espontaneidad revolucionaria» o en la ausencia de una base social campesina donde hay que buscar la causa final del fracaso final de esas escaramuzas armadas ahogadas en sangre. Frente a un Estado que mantiene intactos sus mecanismos de coerción, una es- 
trategia insurrecional basada en apoyos dispersos no puede nunca hacer estallar un disturbio general y acaba siendo fácilmente reprimida. Se anunciaba la revolución para un día ya fijado, generalmente condicionado a lo que hiciera el enemigo, y sin objetivos políticos claros. Nada tiene de extraño, por lo tanto, que el resultado fuera el conocido: las cárceles rebosaron de presos anarquistas y los juzgados de casos calificados de criminales. Por decirlo de forma clara: la República se tiñó de "sangre del pueblo», pero la CNT, heroicidades al margen, ganó poco y perdió mucho. La escisión interna, la persecución de sus militantes y la represión generalizada resultaron malos compañeros de viaje de una organización que aspiraba a meter en sus filas a todo el proletariado.

El ciclo insurreccional no sólo contribuyó a desgarrar las heridas que, abiertas desde el verano de 1931 con el "manifiesto de los Treinta", culminaron en la escisión, sino que inauguró una etapa de recriminaciones y reproches entre los diferentes sectores en pugna que aspiraban a controlar los importantes recursos movilizadores con que contaba la CNT en algunas ciudades españolas.

Varias decenas de miles de militantes, y entre ellos algunos de los más brillantes dirigentes como Joan Peiró o Ángel Pestaña, abandonaron la disciplina cenetista. El descenso de la afiliación desde los primeros meses de 1932 fue acusado. Tras un aumento considerable desde abril de 1931 hasta finales de ese año, que las fuentes consultadas permiten cifrar en unos 300.000 afiliados, la organización entró en un período de crisis del que sólo empezó a recuperarse en la primavera de 1936. Si el punto de referencia lo situamos en el Congreso de junio de 1931, donde aparecieron representados 535.565 afiliados, la CNT había perdido a la altura de enero de 1934, tras el final del ciclo insurreccional y la consumación de la escisión, unos 300.000 afiliados, de los cuales casi 200.000 correspondían a Cataluña; si la comparación se realiza con los afiliados en su momento de apogeo, unos 800.000 a finales de 1931, el descenso superaba el medio millón. Y lo que parece más importante: en su momento más bajo y crítico, los cotizantes reales eran bastantes menos de esos 200.000 afiliados.

Tras las insurrecciones, algo se reflexionó. A las críticas constantes de algunos sindicalistas como Peiró a la inutilidad de esas acciones de «minorías audaces", se sumaron las de otros anarquistas, tanto desde la CNT como de la AIT, que venían a decir lo mismo: motivos para la rebelión es lo que le sobraban al pueblo; pero alcanzado el primer eslabón necesario para la revolución, "el espíritu de rebeldía", a la CNT le faltaba el segundo, el de "organización». Sumar esfuerzos, en vez de dividirlos. Conservar 
energías, en lugar de desgastarlas. Corregir el rumbo que tan tormentoso había resultado.

Corregir el rumbo significaba emprender un camino opuesto al de la insurrección, algo que no podia costar mucho tal y como habian dejado a la CNT las sucesivas refriegas. En el Pleno Nacional de Regionales de enero de 1936, la representación asturiana pidió "que se invite a los sindicatos de oposición a ingresar de nuevo en la CNT». La cosa era factible porque las injurias y calumnias habian bajado de tono tras el fin del ciclo insurreccional, la FAl se sostenia a duras penas en pie y los sindicatos de oposición nunca dejaron de afirmar su posición revolucionaria y antipolítica. para ellos, como declararon reiteradamente, el alejamiento respecto a la CNT era "puramente circunstancial». Salvo el grupo de Pestaña, con Josep Robusté y Marín Civera entre otros, volvieron casi todos los que otrora se habían destacado como dirigentes de la CNT. En total, 69.621 afiliados y 85 sindicatos reingresaron en la organización en el Congreso de mayo de 1936. Un tercio procedia del País Valenciano y el resto, excepto una pequeña representación que se había conservado en Huelva, de Cataluña.

Que escindidos, faistas y anarcosindicalistas que nunca compartieron esas posiciones se fundieran de nuevo en una misma organización mostraba también, al margen del logro que eso pudo suponer, dos cosas. Una, que las dos estrategias enfrentadas, tanto la que trataba de adaptar el sindicalismo revolucionario a la nueva situación política originada por la República como la del radicalismo anarquista que pretendió canalizar el descontento de los trabajadores a través de la vía insurrecional, habian fracasado. Otra, que ninguna de las dos supo ofrecer alternativas a los problemas políticos y sociales más allá de las típicas fórmulas abstractas sobre la destrucción del Estado o la transformación de la sociedad. Así las cosas, los sindicatos de oposición nunca consiguieron arraigar en otros lugares y sectores distintos de los que se llevaron con la escisión, e incluso perdieron por el camino a grupos y dirigentes que se alejaron definitivamente del anarcosindicalismo; y los defensores de la pureza anarquista, enganchados a la bandera de la FAl, arrastraron a la CNT a una situación agónica de la que sólo pudo salir por la convocatoria de unas elecciones generales y por un golpe de Estado que, varios meses después, trajo consecuencias que nunca habian previsto.

La convocatoria de elecciones para el 16 de febrero de 1936 permitió, efectivamente, respirar a la CNT, si por respirar se entiende la posibilidad de ocupar de nuevo el espacio público, movilizar a sus afiliados y reorga- 
nizar sus efectivos, aspiración primordial de cualquier movimiento social. Antes de esas elecciones, la CNT no repitió la machacona campaña abstencionista de 1933. Las diferencias, sin embargo, respecto a 1933 no residía, como tantas veces se ha repetido, en la necesidad de que en 1936 ganara la izquierda para sacar a los presos de las cárceles. La cosa era más sencilla. En 1933 un sector importante del anarcosindicalismo puso la abstención como preámbulo obligado de la revolución y a ésta como consecuencia ineludible de aquélla; en 1936, tal y como estaba el movimiento después de aquella experiencia, a nadie se le ocurrió anunciar la revolución para el día siguiente de las elecciones.

Tampoco hubo necesidad de hacerlo. El Frente Popular salió victorioso de las urnas y eso significó para muchos el segundo acto de una obra iniciada en abril de 1931 e interrumpida en el verano de 1933. Una segunda oportunidad, efectivamente, para Manuel Azaña, de nuevo en el poder y con las multitudes en las calies; para los socialistas, que volvian a poseer una notable influencia política en los poderes locales; y para los anarcosindicalistas, que podian recuperar su capacidad de agitación y algunos de los apoyos sociales perdidos.

Con los datos disponibles, resulta bastante aventurado aceptar la rutinaria afirmación de que España entró en la primavera de 1936 en una oleada de huelgas sin precedentes, "especialmente donde la CNT tenía influencia", o de que ese período constituyó el momento más acusado "de desorden civil en la historia de España».

En primer lugar, la CNT no tuvo especial protagonismo en ese movimiento huelguístico. Pudo tenerlo en Madrid, Málaga y en otros centros urbanos de menor importancia, pero no en Barcelona, Sevilla o Zaragoza, las ciudades donde más implantación había mostrado en el primer bienio. En Sevilla y Barcelona, los anarcosindicalistas no gozaban de buena salud y las cifras que podian esgrimir se encontraban en el punto más bajo de toda la República. Apartados por necesidad de la vía insurreccional, tuvieron que romper también las ataduras ideológicas que más les habían distanciado del régimen republicano. $Y$ al romperlas, volvieron a transitar caminos por donde ya habian pasado en la primavera de 1931. Los indicios, al menos para Barcelona y Zaragoza, son muy claros: entendimiento con las autoridades republicanas, en vez de movilizar a sus afiliados continuamente contra ellas; y disposición a negociar acuerdos contra el paro antes de poner en práctica la acción directa.

Nadie hablaba de renunciar a sus ideas. Pero, con los presos en la calle y sin mártires que reclamar, las preocupaciones dominantes en esos primeros meses de 1936 fueron el paro, las condiciones laborales y, muy 
especialmente la reorganización sindical. Atrás quedaban el tono victimista de sus declaraciones y el lenguaje agresivo contra republicanos y socialistas. Los vientos que soplaban entre los sindicatos de la CNT era muy diferentes a los de 1932 y 1933. Los centros obreros se reabrían. Las heridas ocasionadas por la escisión se cerraban. La prensa confederal, con censuras, pero sin suspensiones, se recuperaba. El Congreso de mayo de Zaragoza, en el que pudieron reunirse 649 delegados de la CNT que representaban a 988 sindicatos y 559.294 afiliados, daba de nuevo motivos para el optimismo, incluso para la euforia.

Que aquel no fue un período álgido de conflictividad social en el mundo rural es algo, por otra parte, que han constatado estudios monográficos recientes. Ni el número ni el tipo de conflictos fue más elevado y acusado de lo que lo había sido desde 1931 a 1934. El cumplimiento de la legislación social, de las bases de trabajo y la creación de contribuciones forzosas para mitigar el problema del paro aparecian entre las exigencias más repetidas durante esos meses. Las sangrientas represiones contra esas manifestaciones campesinas fueron raras, si se compara con lo abundantes que habian sido durante el primer bienio, y la matanza de Yeste (Albacete) del 29 de mayo, donde 17 campesinos fueron acribillados a tiros por la guardia civil, no produjo ninguna movilización social, ningún clamoreo contra esa institución y ni siquiera revitalizó el culto a los mártires tan frecuente en anteriores ocasiones.

No hay que valorar la historia, sin embargo, sólo por los muertos que provoca. La amenaza al orden social y la subversión de las relaciones de clase se percibian con mayor intensidad en 1936 que en los primeros años de la República. La estabilidad política del régimen corría también más peligro. El lenguaje de clase, con su retórica sobre las divisiones sociales y sus incitaciones a atacar al contrario, había impregnado gradualmente la atmósfera española desde que el proyecto reformista de los primeros gobiernos republicanos chocó con obstáculos insalvables. Amplios sectores de la población permanecieron políticamente débiles y se les excluyó, marginados y sin reconocimientos, de la vida política de la nación. Las organizaciones sindicales no buscaban defender los intereses obreros en el marco de las estructuras políticas y económicas existentes, sino que pretendian cambiarlas. Deshecha en 1933 la coalición entre republicanos y socialistas, que tenía como objetivo incorporar a su proyecto a importantes sectores de las clases medias y trabajadores urbanos, el PSOE se alejó de su posición de avance gradual y pacífico hacia el socialismo y alzó la bandera de la revolución. Las elecciones de febrero de 1936 cogieron al movimiento socialista en un proceso de escisión y luchas internas que bloqueó el compromiso de gobierno con los republicanos, una de las pocas 
salidas políticas que podía haber devuelto la estabilidad a la sociedad española del momento.

Dada la fragmentación política en que se encontraban esas clases medias urbanas y la imposibilidad de atraerse a los pequeños y medianos propietarios rurales, resulta muy poco probable que esa coalición de gobierno hubiera modificado las circunstancias nada propicias que concurrian para la consolidación democrática. Porque superado ya el desafío insurreccional que anarquistas y socialistas provocaron desde enero de 1932 a octubre de 1934, la ofensiva más seria contra el régimen republicano la protagonizaron, junto a las viejas oligarquías servidoras de la Monarquía, las fuerzas sociales reclutadas entre los propietarios medios, pobres y "muy probres" rurales, dirigidas por sectores profesionales urbanos que habían hecho de la CEDA el primer partido de masas de la historia de la derecha española. Amparados bajo el techo ideológico del catolicismo, desde el que vincularon la defensa de la religión con la del orden y de la propiedad, asumieron el común objetivo de extirpar la amenaza socialista y libertaria tan arraigada entre las clases trabajadoras rurales y urbanas.

Tampoco esa óensiva habría dado los frutos deseados si no se hubiera podido contar con las armas de un sector importante del ejército. $Y$ así, por la fuerza de las armas y no de la calle, a la que tantas veces había apelado el anarcosindicalismo, le llegó el final a la República. Ese golpe militar encontró resistencia porque la sociedad española de 1936 no era la de 1923. Por ella había pasado una República que abrió la posibilidad histórica de solucionar problemas irresueltos, que encontró importantes factores de inestabilidad y que no puso, o no pudo poner, en marcha los recursos políticos adecuados para solucionarlos. Frente a un nivel de movilización política y social tan amplio como el propiciado por ese escenario, el golpe no podía acabar, como tantas veces en la historia contemporánea de España, en un mero pronunciamiento. Se necesitaba una nueva versión, violenta y definitiva, puesta en marcha ya por el fascismo en otros lugares de Europa, que cerrara la crisis y restaurara, tapándolas de verdad, todas las fracturas abiertas - o agrandadas- por la experiencia republicana.

Toda una etapa concluia para el anarcosindicalismo con ese golpe. Una etapa en la que, como hemos visto, mantuvo relaciones muy difíciles con la República y conoció diferentes estados de ánimo, desde las expectativas iniciales de algunos a las insurrecciones inútiles de otros, pasando por la hostilidad de la mayoría de sus afiliados. Cuando estaban rehaciéndose todos esos caminos, llegó julio de 1936. De súbito, el anarcosindicalismo se encontró con lo que tanto había buscado sin 
éxito, con su oportunidad histórica de hacer realidad el sueño igualitario en un paraíso terrenal. Lo que era en la primavera de 1936 debilidad, incertidumbre, vuelta a empezar, se tornó en el verano en fortaleza e imposición revolucionaria. De la "borrachera de entusiasmo" que trajo el vendaval de abril de 1931 a la "borrachera revolucionaria» originada por la tormenta de julio de 1936. De la fuerza de la calle al poder de las armas.

\section{LA REVOLUCIÓN}

El fracaso de la sublevación militar en las principales ciudades del país transformó el golpe de Estado en guerra civil y significó el inicio de una nueva época donde la lucha de clases iba a resolverse por procedimientos armados.

Esa guerra civil y revolución modificaron los esquemas fundamentales que el anarcosindicalismo había adoptado a lo largo de su historia en el terreno de la organización y de las prácticas sindicales. La clásica crítica del poder político dejó paso, en este período, a la participación de los libertarios en los órganos de gobierno locales y regionales. $Y$ lo que hasta ese momento había sido una mera formulación del objetivo colectivizador, se convirtió en la posibilidad de realizarlo.

El vacío de poder que siguió a la derrota de esa sublevación requería una respuesta organizada, en las calles, en las fábricas, en el frente y en las instituciones. Pero las vías y alternativas que se abrian eran tantas que pocos anarcosindicalistas parecieron captar la gravedad de lo que se avecinaba.

A esas transformaciones políticas y sociales del verano de 1936 y a la creación y organización de milicias, consideradas las manifestaciones del poder popular, siempre les acompañó la violencia. La tea purificadora alcanzó en esas primeras semanas a políticos conservadores, militares, propietarios, burgueses, comerciantes, clero, trabajadores significados en las fábricas por sus ideas moderadas, católicos, técnicos y jefes de personal de las diferentes industrias. Antes de construir, había que eliminar de raíz el mal social y a sus principales causantes. Y la sangre corrió derramada por los múltiples comités de empresa, barrio y pueblo que se crearon al calor de la revolución; por los "grupos de investigación y vigilancia" en cargados de limpiar la atmósfera de gente «malsana». Todo "en bien de la salud pública". Cualquiera podía llevar una pistola o fusil en aquel momento; en las calles y en las fábricas. 
En las primeras semanas de guerra, por lo tanto, la «caza de fascistas", la defensa de la revolución y la persecución de sus adversarios fueron fenómenos inextricablemente unidos y en la práctica resultaba muy difícil hallar la línea divisoria. Tal violencia empezó con la eliminación de quienes habian participado en la sublevación contra la República, siguió como una tarea urgente para suprimir la contrarrevolución y desembocó en una cuestión de ley y orden revolucionarios. Había llegado por fin la hora de que el pueblo se liberara de sus cadenas y muchos compartieron entusiasmados esa retórica extremista. El fuego purificador alcanzó con especial virulencia al clero. De los reproches éticos y las actitudes ofensivas, elementos comunes a la cultura anticlerical de republicanos, socialistas y anarquistas desde principios de siglo, se pasó definitivamente a la acción.

Esa atmósfera cálida del verano de 1936 envolvió también el nacimiento de las colectivizaciones campesinas. La explotación común se organizó principalmente en aquellas tierras que habían sido abandonadas por sus propietarios o en las fincas incautadas directamente por grupos armados y por los comités revolucionarios. Muchos anarcosindicalistas creyeron que con la destrucción de la legalidad vigente y ese cambio de propietarios, la revolución era ya una cosa hecha. Los acontecimientos de julio de 1936 habían proporcionado, efectivamente, un ascenso fulminante a la CNT. En Cataluña y en la mitad oriental de Aragón, sus militantes de siempre se imaginaban dueños absolutos de la situación. Ya no eran "desheredados", carne de presidio, blanco favorito de la reacción y de los gobernantes. Ahora el puebio -es decir, ellos- estaba armado y nada ni nadie podría detenerlo. Todos querían tener un carné de la histórica CNT. Solidaridad Obrera, que se repartió gratis en los primeros días en las calles de Barcelona, alcanzó pronto su apogeo, con tanta gente ávida de noticias frescas sobre la guerra y la revolución. Su tirada se disparó: los 31.000 ejemplares de comienzos de julio pasaron a 70.000 pocos días después de la sublevación y a 150.000 a finales de agosto.

Pero por muy destructiva y radical que se manifestara en el verano de 1936, la revolución no había hecho, sino empezar. Los acontecimientos enseguida demostraron que el horizonte no estaba tan despejado. La brecha abierta por los revolucionarios con la victoria conseguida en Barcelona ni siquiera pudo extenderse hasta Zaragoza. Después de unas semanas en que todas las organizaciones políticas parecian aprobar esas formas de expresión del poder popular, de derribo del viejo orden, muy pronto quedó claro que el proceso revolucionario -o lo que otros definían como un combate contra el fascismo en una guerra civil- era 
en primer lugar una lucha por el poder político y militar. Una pugna por controlar las armas y los cambios por ellas favorecidos; por reconstruir ese Estado debilitado por la sublevación y el empuje popular. La incapacidad de los anarcosindicalistas para articular los dispersos poderes revolucionarios en una política global les condenó a partir del otoño de 1936 a ser actores de segunda fila. Llegaron al gobierno cuando los mejores asientos estaban ya ocupados. Improvisada, sin programa claro, subordinada a la guerra y acosada por múltiples enemigos, la revolución se congeló. Mal organizadas, peor pertrechadas y con escasa disciplina, las milicias languidecieron hasta su incorporación definitiva al nuevo ejército de la República. En el verano de 1937 no quedaban ni los restos de aquellas jornadas gloriosas de julio de 1936. En menos de un año, la apuesta del anarcosindicalismo mostró su fragilidad. Esa fue su edad de oro, corta edad de oro.

La CNT en el gobierno: "Hecho transcendental", decía Solidaridad Obrera ese mismo 4 de noviembre. No era para menos: «El Gobierno (...) ha dejado de ser una fuerza de opresión contra la clase trabajadora, asi como el Estado no representa ya al organismo que separa a la sociedad en clases. Y ambos dejarán aún más de oprimir a pueblos con la intervención en ellos de elementos de la CNT». Nunca los dirigentes anarconsindicalistas habian dicho eso de un gobierno ni habían confiado de esa forma en los poderes de la acción gubernamental. La guerra y la revolución habían cambiado, no obstante, esa percepción o al menos así lo creían ellos en ese momento.

La CNT en el gobierno, aunque tarde, si de lo que se trataba era de no dejar las decisiones en poder de otros, y aceptando cuatro ministerios - Justicia, Sanidad, Comercio e Industria- que poco tenían que decir en los grandes problemas que afectaban al Estado, a la revolución y a la guerra. Los libertarios tuvieron que tolerar una política agraria que no compartían, estuvieron siempre ausentes de las resoluciones en materia militar y para la aplicación de su política industrial Joan Peiró encontró serios obstáculos en los gobiernos autónomos de Cataluña y el País Vasco, precisamente las zonas donde estaban localizadas las principales industrias. Ahí y no tanto en la decisión asumida de participar en el gobierno residen los motivos de lo que después fue calificado como "fracaso": eligieron el camino sin las alforjas necesarias para emprenderlo. Los libertarios, que como consecuencia del derrumbamiento del poder republicano participaban en las actividades políticas a través de organismos que ellos mismos crearon (comités revolucionarios, consejos locales de administración, consejos provinciales y regionales de defensa), se mostraron incapaces de plasmar todo eso en una política global cuando les llegó la 
hora. Incapacidad que esperaban, y deseaban, también las restantes fuerzas políticas. Mejor que estuvieran dentro que fuera. Chocarian con la dura realidad del poder y de la guerra y tendrían que abandonar su retórica y extremismos revolucionarios. $Y$ sin ellos, la CNT quedaria en nada.

Aunque evidentemente no todas las reacciones fueron tan entusiastas como la de Solidaridad Obrera, no hay demasiados indicios de que la entrada de la CNT en el gobierno abriera una brecha entre los comités dirigentes - que controlaban el aparato de prensa y propaganda, participaban en los diversos gobiernos regionales y marcaban las líneas de actuacióny los militantes de los sindicatos y colectivizaciones. Si se rastrean minuciosamente las fuentes disponibles, no hay duda de que los principales grupos de dirección -el Comité Nacional y los regionales de Cataluña, País Valenciano y Aragón-y los órganos de expresión más influyentes propiciaron y asumieron ese paso. Las resistencias de la "base», de esa base sindical a la que siempre se supone revolucionaria frente a los dirigentes reformistas, fueron mínimas, y estuvieron, como veremos, mucho más relacionadas con las consecuencias que a esa decisión se atribuyen que con la propia decisión.

En realidad, la ruptura de ese equilibrio, muy ostensible finalizada la guerra, llegó con los sucesos de mayo de 1937, cuando comenzó a considerarse a la colaboración el mayor "error» histórico de la CNT y a los "colaboracionistas" sus célebres responsables. Fue a partir de esos hechos cuando la crítica anarquista del poder adquirió especial virulencia en núcleos de las Juventudes Libertarias de Cataluña y del frente de Aragón y en grupos como "Los Amigos de Durruti» que habían mostrado ya una fuerte oposición a la militarización. Todas las memorias y testimonios posteriores, desde García Oliver a Federica Montseny, pasando por Ricardo Sanz o Antonio Ortiz, se sumaron a esa cantinela: la entrada en el gobierno de Largo Caballero había significado la renuncia absoluta a los principios antipolíticos y revolucionarios.

Del paso de la CNT por el gobierno quedaron escasas huellas. Entraron en noviembre de 1936 y se fueron en mayo de 1937. Poco pudieron hacer en seis meses. Se ha recordado mucho más lo que significó la participación de cuatro anarquistas en un gobierno que su actividad legislativa. Como la revolución y la guerra se perdieron, nunca pudieron aquellos ministros pasear su dignidad por la historia. Y como no podía ser menos, a semejante acto de ruptura con la tradición antipolítica se le achacaron todas las desgracias. Para la memoria colectiva del movimiento libertario, derrotado y en el exilio, de aquelia traición, de aquel error sólo podían derivarse funestas consecuencias. Toda la literatura anarquista posterior, 
cuando se enfrentó a ese tema, dejó el análisis a un lado para descargar la retahíla de reproches éticos harto conocidos. A un lado quedaba la revolución, vigorosa, soberana; al otro, su destrucción, hecha realidad por la ofensiva que desde el poder se emprendió contra las milicias, los comités revolucionarios y las colectivizaciones, las tres solemnes manifestaciones del cambio revolucionario. Se menospreció así, en ese ajuste de cuentas con el pasado, lo que de necesario y positivo hubo en aquel giro extraordinario. Necesario, porque la revolución y la guerra, que los anarquistas no habian provocado, obligaron a articular una solución que, evidentemente, debía alejarse de las doctrinas y actitudes que históricamente les habían identificado. Positivo, porque esa defensa de la responsabilidad y de la disciplina, que convirtió precisamente la participación en el gobierno en uno de sus símbolos, mejoró la situación en la retaguardia, evitó bastantes más derramamientos inútiles de sangre de los que hubo y contribuyó a mitigar la resistencia que la otra estrategia disponible, la maximalista y de enfrentamiento radical con las instituciones republicanas, había alimentado.

Sobre la cuestión tantas veces planteada de si los anarquistas podían, - debían, haber optado por imponer su dictadura revolucionaria, en vez de colaborar con un gobierno de socialistas, republicanos burgueses y comunistas, hay pocas cosas que añadir. La revolución era para los anarquistas el derrumbe del orden existente y la destrucción de todos sus símbolos. De ahí que confundieran lo que era el primer acto del drama revolucionario con su consumación definitiva. Cuando se dieron cuenta que aquello no acababa en las calles de Barcelona o en los campos de Aragón, que no estaban solos, que no todos los obreros industriales, y menos aún los campesinos, estaban afiliados a la CNT, que una revolución dentro de una guerra, subordinada a ella, dejaba escaso margen para la elección, se vieron obligados a cambiar su retórica y sus manifestaciones prácticas. Con el bagaje disponible, la conquista del poder central era inalcanzable. Porque estaba claro que el asalto al poder, o la instauración de una dictadura revolucionaria, debía hacerse con el mismo procedimiento que había servido para derrumbar la legalidad existente: por las armas. Desde Barcelona, la CNT no tenía posibilidad alguna para hacerlo. $Y$ en Madrid, imposible tanto la acción conjunta obrera como la destrucción de la legalidad republicana, no quedaban muchas más opciones que la que se tomó: incorporarse a un gobierno en el que estaban representados todas las fuerzas políticas que se opusieron a la rebelión militar.

Tras los trágicos sucesos de mayo de 1937, una «guerra civil» dentro del bando republicano que sólo en Barcelona dejó por las calles cuatro- 
cientos muertos y mil heridos, la revolución dejó de ser la referencia ineludible, aquella fuerza devastadora que se había llevado por delante al viejo orden. Desapareció de la agenda de la CNT, incluso de su discurso.

El movimiento entró, desde la primavera de 1938, en fase de liquidación. Cada vez quedaba menos territorio que defender. Unos meses después todo había acabado. Tras la conquista por el ejército de Franco de todo el territorio fiel a la República, el orden social fue restablecido con la misma rapidez con que había sido derrocado. Las cárceles, las ejecuciones y el exilio metieron al anarcosindicalismo en un túnel del que ya no volvería a salir.

\section{EL DESARRAIGO}

La etapa de clandestinidad que se abrió en 1939 nada tenía que ver con las precedentes, con aquellas tan frecuentes en las primeras décadas de la historia del anarquismo español. Era el resultado de la derrota en una guerra, impuesta a sangre y fuego, inmisericorde. La vida sindical era imposible ; tampoco existía el marco mínimo de libertades que había permitido en otras épocas, incluso en las más duras, las polémicas doctrinales y los esfuerzos culturales -en forma de folletos, periódicos y ateneos- para acercarse al "pueblo". Escapar a la persecución, burlar a la policia, enfrentarse a las fuerzas armadas, practicar la "gimnasia revolucionaria", había dejado de ser un juego, una aventura, como lo había sido para algunos "hombres de acción", como Ascaso y Durruti, durante los años que siguieron al golpe de Primo de Rivera, incluso durante la República. Resultaba muy difícil, bajo las condiciones inauguradas por el final de la guerra, desarrollar el culto a ese pueblo, elucubrar sobre la sociedad futura, soñar con utopías. Eso era ya historia, cercana, pero pasada, la gran ocasión perdida, abortada por la guerra y los rivales comunistas, aniquilada por las armas franquistas. Ahora no había, sino silencio en el interior y duras polémicas, enfrentamientos divisores y escisiones en el exilio. La mayoría, bastante tenía con sobrevivir, con buscar un lugar, bien lejos, en el que acomodarse. Hasta el final de la Segunda Guerra Mundial hubo esperanzas. Muchos anarquistas se enrolaron en la resistencia francesa contra el nazismo, pensando que aquella era todavía su guerra, la que acabaría con todos los tiranos, y Franco era el mayor de ellos, la que le permitiría volver a sus casas, a sus trabajos y a sus tierras. Pero murieron Hitler y Mussolini, las potencias del Eje fueron derrotadas, y Franco siguió. Y siguió recordando la guerra y administrando un amargo castigo a quienes la habían perdide. 
Mas no fueron sólo la larga dictadura y el terror contrarrevolucionario los que se engulleron al anarcosindicalismo y le impidieron volver, renacer tras la muerte de Franco. Las distancias existentes entre 1939 y 1975 parecían insalvables. Había emergido una nueva cultura política y sindical. Se había impuesto la negociación como forma de institucionalizar los conflictos. Nuevos movimientos sociales y nuevos protagonistas habian sustituido a los de clase, a los de esa clase obrera a la que se le asignaba la misión histórica de transformar la sociedad. Los trabajadores del campo que acudieron en masa a las ciudades desde los años cincuenta lo hacian para incorporarse en sectores industriales muy diversos y no sólo, como había ocurrido con la emigración de los años veinte, en la construcción y en sectores siempre a caballo entre la agricultura y la industria. El proletariado rural había descendido considerablemente y ya no protagonizaba huelgas. El analfabetismo se había reducido de forma drástica y ya no era, como se declaraba en el Congreso de la CNT de 1931, esa «lacra (...) que tiene hundido al pueblo en la mayor de las infamias".

Los factores ambientales y culturales que habian permitido en épocas anteriores la apelación a mitos ancestrales y mesiánicos, eso que Brenan llamaba la "religiosidad al revés", fáciles de reconocer en el anarquismo, pero también en otros movimientos obreros de tipo marxista, eran ya historia. Aquel Estado débil, que había posibilitado la ilusión y el sueño de que las revoluciones dependian sólo de las intenciones revolucionarias de obreros y campesinos, se habia mudado en uno más fuerte, eficaz, intervencionista, casi "benefactor». El consumo hacía milagros: permitía al capital extenderse y a los obreros mejorar su nivel de vida. Sin el antipoliticismo, y con obreros que abandonaban el radicalismo ante la perspectiva de mejoras tangibles e inmediatas, que preferían el coche y la nevera al altruismo y al sacrificio por la causa, el anarquismo flaqueaba, dejaba de existir.

El panorama que ofrecian los anarquistas históricos, los que han sido objeto de este estudio, en los últimos años del franquismo era desalentador: viejos, algunos ya muy viejos, destrozados por un exilio que nunca logró recomponer a los diferentes grupos rivales, diseminados por Francia y los países latinoamericanos, vivian para recordar, con una mezcla de nostalgia, rabia y orgullo, aquellos años heróicos en los que habían constituido una fuerza social de cambio. Cuando, muerto Franco, pudieron de nuevo pisar suelo español, los campos, los pueblos, las ciudades, las personas, habian cambiado. La posibilidad de recuperar al anarcosindicalismo como movimiento de masas era nula. Podian mantener ellos sus principios, y los mantuvieron, y continúan, hasta la tumba. Poco más les quedaba: la memoria, que era suficiente. La guerra y la cruel dictadura los desarraigó. Los cambios que se produjeron desde los años cincuenta en la 
estructura social les impidieron echar de nuevo raíces. No tenían alternativa. Estaban solos y sin posibles aliados políticos, nacionales o internacionales, algo con lo que podía contar, por ejemplo, la UGT, el otro sindicalismo destrozado por las divisiones internas y por la represión. Ni siquiera les devolverían el patrimonio que reclamaban. Ellos, definitivamente, pertenecian a esa España en ruinas sobre la que se había levantado el milagroso desarrollo.

\section{BIBLIOGRAFÍA GENERAL}

Hace ya años que Josep TeRmEs trató las líneas interpretativas del arraigo de la I Internacional en España: Anarquismo y sindicalismo en España. La Primera Internacional (1864-1881). Crítica, Barcelona, 1977. Sobre el mismo asunto, más centrada en los movimientos campesinos, puede verse Clara E. LIDA. Anarquismo y revolución en la España del XIX. Siglo XXI, Madrid, 1972. Como texto de la época resulta imprescindible recurrir a El proletariado militante, de Anselmo LoREnzo del que existe una edición de Alianza Ed., Madrid, 1974, a cargo de José Álvarez Junco. A este autor le debemos la aproximación más exhaustiva al conocimiento global del tema que nos ocupa: La ideologia política del anarquismo español (1868-1910), Siglo XXI, Madrid, 1976 (edición corregida en 1991).

El complicado tema de la "propaganda por el hecho" está bien resumido en R. NúNEz FloRENCIO, El terrorismo anarquista (1888-1909). Siglo XXI, Madrid, 1983. Sobre Andalucía resulta útil la síntesis de Jacques MaURICE, El anarquismo andaluz. Campesinos y sindicalistas, 1868-1936, Crítica, Barcelona, 1990, aunque conviene recordar que fue T. KAPLAN quien se aproximó al asunto ya hace años, con polémica incluida (véase J. ÁLVAREZ JUNCO, "Sobre el anarquisrio y el movimiento obrero andaluz". Estudios de Historia Social, 10-11, 1979), en Origenes sociales del anarquismo en Andalucia. Capitalismo agrario y lucha de clases en la provincia de Cádiz, 1868-1903, Crítica, Barcelona, 1977. La principal deuda, sin embargo, siempre será con el clásico Historia de la agitaciones campesinas andaluzas, de Juan DiAz DEL MORAL, con edición de Alianza en 1973 (la primera, en 1929).

Sobre los resortes culturales de la ideología anarquista para atraerse a las capas populares ha tratado J. ÁlvAREZ JUNCO erı "La sucultura anarquista en España: racionalismo y populismo", en Culturas populares. Diferencia, divergencias, conflictos. Casa de Velázquez, Universidad Complutense, Madrid, págs. 197-208. Una compilación que, aunque desigual, muestra las nuevas preocupaciones de muchos autores sobre el tema en Bert HofmanN, Pere JOAN i Tous y Manfred TIETZ (eds.), El anarquismo español y sus tradiciones culturales, Vervuert-lberoamericana, Frankfurt am Main-Madrid, 1995. Precursora de los estudios sobre la relación entre arte, anarquismo y literatura fue Lily LiTVAK, Musa libertaria. Arte, literatura y vida cultural del anarquismo español (1880-1913). Antoni Bosch, Barcelona, 1981. Sobre educación puede verse Clara E. LIDA, "Educación anarquista en la España del ochocientos". Revista de Occidente, 97 (1971), págs. 33-47; Pere SolA | GussinyeR. Educació i Moviment Libertari a Catalunya (1901-1939), Edicions 62, Barcelona, 1980; y Alejandro TIANA Ferrer. Educación libertaria y revolución social (España, 1936-1939), UNED, Madrid, 1987.

El nacimiento de la CNT tiene su obra institucional en Xavier CUADRAT, Socialismo y anarquismo en Cataluña (1899-1911). Los origenes de la CNT. Ediciones de la Revista de Trabajo, Madrid, 1976. Pero sobre la Barcelona de ia primera década de nuestro siglo existe una bibliografía excelente que pasa por Joan Connelly UlLman, La Semana Trágica. Estudio sobre las causas socioeconómicas del anticlericalismo en España (1898-1912). Ariel, Barcelona, 1972; siguiendo con Joaquín Romero MAURA, "La Rosa de Fuego". El obrerismo barcelonés de 1899 a 1909. Grijalbo, Barcelona, 1874; Joan B. CULLA I CLARA, Ei republicanisme lerrouxista a Catalunya (1901-1923), Curial, Barcelona, 1986; hasta llegar a José Álvarez JunCO, El emperador del Paralelo. Lerroux y la demagogia populista, Alianza Ed., Madrid, 1990.

Los primeros años de consolidación de la CNT están examinados, con un detallado tratamiento institucional e ideológico, en A. BAH, La CNT En los años rojos. Del sindicalismo revo- 
lucionario al anarcosindicalismo (1910-1926). Akal, Madrid, 1981. Resulta también útil G. MEAKER, La izquierda revolucionaria en España. 1914-1923, Ariel, Barcelona, 1978. Las actitudes de la CNT ante la Primera Guerra Mundial están tratadas en Carlos ForCADELL, Parlamentarismo y bolchevización. El movimiento obrero español, 1914-1918, Crítica, Barcelona, 1978. Sobre Barcelona queda todavia el estudio pionero de A. BALLCELLS, El sindicalismo en Barcelona, 1916-1923, Barcelona, 1965. Una buena reconstrucción novelada de esos años la proporcionó Eduardo MENDOza en La verdad sobre el caso Savolta (Seix Barral). Sobre la Dictadura de Primo de Rivera continúa en vigor, porque en realidad no hay otra cosa, el análisis que ya hace años hizo. A. ElorzA, "El anarquismo español bajo la Dictadura», en Revista de Trabajo, n. ${ }^{o s} 39-40$ y $46(1972,1973-1974)$.

Una sintesis general se encuentra en Javier Paniagua, Anarquistas y socialistas, Historia 16. Madrid, 1989. Del mismo autor puede verse el reciente estado de la cuestión sobre las explicaciones dadas a su arraigo, "Una gran pregunta y varias respuestas. El anarquismo español: desde la politica a la historiografía", Historia Social, 12 (1992), págs. 31-57. Existe también un buen resumen de su trayectoria, desde su penetración hasta la guerra civil, en Pere GABRIEL, "El anarquismo en España", en G. Woodcock, El anarquismo, Ariel, Barcelona, 1979, págs. 330-388. Existen muchos ejemplos de aproximaciones militantes al tema, pero la más útil y documentada es la de J. PEIRATS, La CNT en la revolución española, Ruedo Ibérico, 1971, tres tomos. De las muchas memorias, la más interesante y provocadora son las de Joan GaRcia OLIVER, El eco de los pasos, Ruedo lbérico, Barcelona, 1978.

La historia del anarcosindicalismo español en los años de la Segunda República y la guerra civil la he abordado recientemente en De la calle al frente. El anarcosindicalismo en España (1931-1939), Crítica, Barcelona, 1997, donde se incluye una interpretación sobre el desarraigo y un apéndice en el que se recogen los argumentos básicos utilizados por los historiadores sobre los orígenes y evolución del anarquismo en España. Un balance historiográfico de ese periodo lo he aportado también en "Guerra civil, ¿lucha de clases?: el difícil ejercicio de reconstruir el pasado". Historia Social, 20 (1994), págs. 135-150.

La primera obra que se aproximó con un minimo rigor a la historia de la CNT en los años republicanos fue Anarcosindicalismo y revolución en España (1930-1937), de John Brademas (Ariel, Barcelona, 1974) y, curiosamente, más de treinta años después -porque en realidad la investigación fue concluida por el autor cuando era estudiante en Oxford a comienzos de los cincuenta-, constituye casi el único punto de referencia general para aquellos interesados en el relato institucional del sindicalismo cenetista durante aquel periodo. Disponemos, sin embargo, de algunos buenos análisis de las diveras manifestaciones doctrinales que supuestamente guiaban su práctica revolucionaria. Antonio ElorzA se adelantó a casi todos en ese tema con La utopia anarquista bajo la Segunda República, Ayuso, Madrid, 1973. Más elaborado y con planteamientos más ambiciosos resulta el estudio de Xavier PaniaguA, La sociedad $/ i$ bertaria. Agrarismo e industrialización en el anarquismo español (1930-1939), Crítica, Barcelona, 1982. La división interna de la CNT, un tema recurrente y cargado de tópicos, está bien abordado en los libros de Eulàlia VEGA, El trentisme a Catalunya. Divergències ideològiques en la CNT (1930-1933). Curial, Barcelona, 1980; y en Anarquistas y sindicalistas durante la Se. gunda República, Institución Alfonso el Magnánimo, 1987.

Una buena reconstrucción de todas esas cuestiones desde marcos regionales o locales se encuentra en Ángeles BARRIO ALONSO, Anarquismo y anarcosindicalismo en Asturias (18901936). Siglo XXI, Madrid, 1988; Ángeles GonZÁLEZ FERNÁNDEZ, Utopía y realidad: anarquismo, anarconsindicalismo y organizaciones obreras. Sevilla, 1900-1923, Diputación de Sevilla, Sevilla, 1996; Enrique Montañés, Anarcosindicalismo y cambio politico. Zaragoza, 1930-1936, Institución Fernando el Católico, Zaragoza, 1989; y Graham Kelsey, Anarcosindicalismo y Estado en Aragón: 1930-1938, Fundación Salvador Seguí-Institución Fernando el Católico, Madrid-Zaragoza, 1994; sin olvidar los estudios pioneros de Albert BaLCELLS para Cataluña (Crisis económica y agitación social en Cataluña de 1930 a 1936; El arraigo del anarquismo en Cataluña...). Existen también otras monografias locales recientes donde se ofrecencen interpretaciones muy sugerentes relacionadas con el anarcosindicalismo: Santos JuLIA, Madrid, 1931 1934. De la fiesta popular a la lucha de clases, Siglo XXI, Madrid, 1984; Enric UCELAY DA CAL, La Catalunya Populista. Imatge, cultura i politica en l'etapa reppublicana (1931-1939). La Magrana, Barcelona, 1982; Salvador FORNER, Industrialización y Movimiento obrero. Alicante, 19231936. Institución Alfonso el Magnánimo, Valencia, 1982; y José Manuel Macarro, La Utopía revolucionaria. Sevilla en la Segunda República, Monte de Piedad y Caja de Ahorros, Sevilla, 1985. 
La bibliografía sobre el anarquismo andaluz y sus conexiones con la sociedad rural cuenta también con abundantes y desiguales aportaciones. Una interpretación global en la ya citada de Jacques MaURICE, El anarquismo andaluz. Campesinos y sindicalistas. 1868-1936. No abundan, sin embargo, estudios novedosos sobre el insurreccionalismo anarquista. El mismo MAURICE publicó con G. BreY un librito sobre el que ya han llovido demasiados años: Historia y leyenda de Casas Viejas, ZYX, Madrid, 1976. Lo mejor sobre ese tema está, no obstante, en inglés y es de Jerome R. MiTnz, The Anarchists of Casas Viejas. The University of Chicago Press, 1982. Para la del Alto Llobregat, puede verse Cristina BORDERias y Mercedes VILANOVA, "Cronología de una insurrección: Figols en 1932", Estudios de historia social. núms. 24-25 (1983), págs. 187-199.

Recordemos, por último, que balances historiográficos recientes sobre el anarquismo en los años trienta se encuentran en Eulàlia VEGA, "Anarquismo y sindicalismo durante la Dictadura y la República"; y Julián CASANOVA, "Guerra y revolución: la edad de oro del anarquismo español», ambos en Historia Social, 1 (1988), págs. 55-76. Puede recurrirse también al amplio catálogo que se ofrece en María Gloria NUNNEZ PÉREZ, Bibliografía comentada sobre la Segunda República Española (1931-1936), Fundación Universitaria Española. Madrid 1993. Para el asunto más específico de las colectivizaciones puede verse Aurora Bosch, "Las colectivizaciones: estado de la cuestión y aspectos regionales», en Josep FonTina et al., La II República Una esperanza frustrada, Alfons el Magnànim, Valencia, 1987, págs. 147-68; Julián CASANOva. "Guerra y revolución: La edad de oro del anarquismo español", Historia Social, 1 (1988), págs 63-76; y Javier PANIAGUA. "La perspectiva histórica de las colectivizaciones (1936-1939)", en J Casanova, comp., El sueño igualitario. Campesinado y colectivizaciones en la España republicana, 1936-1939, Institución Fernando el Católico, Zaragoza, 1988.

De las numerosas obras dedicadas al tema por los protagonistas de los hechos, destacan las de Agustín Souchy, Entre los campesinos de Aragón. El comunismo libertario en las comarcas liberadas. Tusquets, Barcelona, 1977; Antonio Rosado, Tierra y libertad. Memorias de un campesino anarcosindicalista andaluz, Critica, Barcelona, 1979; y, especialmente, Gastón Leval, Colectividades libertarias en España, Proyección, Buenos Aires, 1972, 2 vols. (también en Aguilera, Madrid, 1977). Una profundización en el mismo discurso, que incluye, no obstante, material del Archivo de Salamanca, puede verse en Frank MINTZ, La autogestión en la España revolucionaria, L.as Ediciones del la Piqueta, Madrid, 1977. Como se sabe, los testimonios de bastantes prctagonistas han sido magistralmente explotados por Ronald FraSER en Recuérdalo tú y recuérdalo a otros. Historia oral de la guerra civil, Crítica, Barcelona, 1979 (2 tomos). La presencia de las mujeres en las experiencias revolucionarias durante la guerra civil ha sido examinada con rigor por Mary NASH, Defying Male Civilization: Women in the Spanish Civil War, Arden Press, Denver, Colorado, 1995.

Una reconstrucción de ese pasado a traves de la vía regional se encuentra en Luis GarRIDO, Colectividades agrarias en Andalucía: Jaén (1931-1939), Siglo XXI, Madrid, 1976 (y en su más reciente Riqueza y tragedia social. Historia de la clase obrera en la provincia de Jaén (18201939), Diputación Provincial de Jaén, (1990); Aurora Bosch, Ugetistas y libertarios. Guerra civil y revolución en el Pais Valenciano, 1936-1939, Alfons el Magnànim, Valencia, 1983: Natividad Rodrigo, Las colectividades agrarias en Castilla-La Mancha, Servicio de Publicaciones de la Junta de Comunidades de Castilla-La Mancha, Toledo, 1985; Julián Casanova, Anarquismo y guerra civil en la sociedad rural aragonesa, 1936-1938, Siglo XXI, Madrid, 1985; y Anna Monjo i Carme VEGA, Els Treballadors i la guerra civil, Editorial Empúries, Barcelona, 1986.

Un estudio general sobre el anarquismo en ese periodo se encuentra en Walther L. BERNECKER, Colectividades y revolución social. El anarquismo en la guerra civil española, 19361939. Crítica. Barcelona, 1982. Un balance e interpretación de todas esas investigaciones monográficas aparece en Julián CASANOVA, "Las colectivizaciones", en La guerra civil. Historia 16. n. 16 (1986), págs. 42-62. Sobre socialismo y colectivizaciones puede consultarse, además de toda la información proporcionada por esos estudios regionales, los artículos de Luis GarRIDO y Julián CASANOVA incluidos en Santos JuLIA, comp., Socialismo y guerra civil, Fundación Pablo Iglesias, Madrid, 1987.

Sobre el peculiar caso catalán y sus colectivizaciones industriales existe también una numerosa y variada bibliografia. Una obra que abrió caminos fue la de Josep MARIA BrICALL, Política economica de la Generalitat (1936-1939), Ediciories 62, Barcelona (2 vols. 1978 y 1979). La mejor descripción del escenario catalán en los años treinta en Enric UCELAY DA CAL, La Catalunya Populista. Imatge. cultura i politica en I' etapa republicana (1931-1939), La Magrana, Barcelona. 1982. 